\title{
Enriquecimento de pão com proteínas de pescado
}

\author{
Bread enrichment with fish protein
}

\section{Graciela Salete CENTENARO ${ }^{1 *}$, Vivian FEDDERN ${ }^{1}$, Eliza Timm BONOW ${ }^{1}$, Myriam SALAS-MELLADO ${ }^{1}$}

\section{Resumo}

Este trabalho teve como objetivos elaborar pães enriquecidos com proteína de pescado para aumentar o conteúdo deste nutriente no produto e avaliar estes pães sensorial, tecnológica e físico-quimicamente. A proteína de pescado foi obtida a partir de cabrinha (Prionotus punctatus), espécie de baixo valor comercial. Para obtenção da polpa de cabrinha, a matéria-prima foi submetida a um processo de lavagem, seguido de secagem. Foram desenvolvidas cinco formulações de pão: 30, 40 e 50\% de polpa lavada úmida (PU) e 3 e $5 \%$ de polpa lavada seca (PS) em base à farinha. Os pães foram avaliados sensorial (teste de ordenação, escala hedônica e perfil de atributos), tecnológica (notas das características internas, externas e volume específico) e físico-quimicamente (composição centesimal). O teste de perfil de atributos mostrou que o pão com $5 \%$ PS não diferiu significativamente $(\alpha=0,05)$ do padrão para nenhum atributo avaliado. Todos pães apresentaram aceitação superior a $74 \%$, no entanto ocorreu diminuição das notas das características internas e externas e do volume específico dos pães com o aumento da adição de polpa em todas as formulações, caracterizando queda da qualidade tecnológica. Os pães com 3 e $5 \%$ de PS e $50 \%$ de PU apresentaram um aumento no conteúdo protéico de 31, 45 e 48\% respectivamente, em relação ao conteúdo protéico do pão padrão.

Palavras-chave: pão; cabrinha; polpa; proteína; enriquecimento.

\begin{abstract}
This work had as objectives to elaborate breads enriched with minced meat of fish and evaluate them sensorial, technological and physicochemically. The fish protein was obtained from cabrinha (Prionotus punctatus), a low commercial value specie. To obtain the minced fish, the grinded meat was submitted to three wash steps with water, resulting the wet washed minced fish (WWMF). When the WWWF was dried and sifted, it was obtained the dry washed minced fish (DWMF). Five bread formulations with addition of 30,40 and $50 \%$ of WWMF and 3 and $5 \%$ of DWMF were tested. All breads obtained were evaluated sensorial (preference test ranking, nine-point hedonic scale and attribute profile), technological (specific volume and technological score for the external and internal characteristics) and physico-chemically (centesimal composition). The attribute profile test showed that the bread containing $5 \%$ DWMF didn't differ significantly $(\alpha=0.05)$ from the bread without addition of fish protein in any attribute. All formulations showed an acceptance index higher than $74 \%$, however it was observed a decreasing of technological score and specific volume values with the increasing amount of minced fish in all formulations, resulting technological quality loss. Breads containing 3 and 5\% of DWMF and 50\% of WWMF presented a protein increase of 31, 45 e $48 \%$, respectively, when compared to the protein of the bread without addition of fish.

Keywords: bread; cabrinha; minced fish; protein; enrichment.
\end{abstract}

\section{Introdução}

O pão é um dos alimentos mais consumidos e uma das principais fontes calóricas da dieta de muitos países e, por esse motivo, vem sendo alvo de muitos estudos de enriquecimento ${ }^{6}$. A fortificação de alimentos com nutrientes é uma prática aceita e empregada pelos processadores de alimentos desde a metade do século $\mathrm{XX}^{10}$ e tem como objetivos reforçar o valor nutritivo e prevenir ou corrigir deficiências de um ou mais nutrientes ${ }^{3}$.

Nossa dieta contém uma ampla variedade de proteínas de diferentes fontes. É geralmente aceito que a concentração relativa de aminoácidos essenciais na dieta é o fator mais determinante no valor nutricional da proteína de um alimento. Proteínas derivadas de fontes animais, a exemplo dos peixes, são consideradas nutricionalmente superiores àquelas de origem vegetal, pois elas contêm um melhor balanço de aminoácidos essenciais para a dieta ${ }^{7}$.

Entretanto, o Brasil apresenta um dos mais baixos índices de consumo de pescado. A oferta de produtos derivados

Recebido para publicação em 17/11/2006

Aceito para publicação em 24/7/2007 (002070)

Departamento de Química, Laboratório de Tecnologia de Alimentos,

Fundação Universidade Federal do Rio Grande - FURG,

Rua Eng. Alfredo Huch, 475, CP 474, CEP 96201-900,

Rio Grande - RS, Brasil

E-mail: gracentenaro@yahoo.com.br

* A quem a correspondência deve ser enviada de pescado e a diversificação na linha de produtos de origem marinha poderão incentivar o consumo destes produtos.

Como o pão constitui uma fração altamente significativa na produção de alimentos, é necessária a formulação de pães contendo proteínas de origem animal que possam estar presentes na mesa do consumidor de todas as classes sociais. O pão é considerado um alimento deficiente em proteínas, assim a aplicação de tecnologia para a conversão de pescado em uma fonte protéica é um método alternativo para um melhor aproveitamento de espécies sem valor comercial, transformando-as em uma nova fonte alimentar ${ }^{9}$.

Diante disso, a complementação protéica do pão, utilizando polpa de pescado, apresenta-se como uma alternativa viável, pelo fornecimento de todos os aminoácidos essenciais, tornando este produto de fácil aceitação, podendo atingir o público de baixo poder aquisitivo.

\section{Material e métodos}

\subsection{Elaboração da polpa de pescado}

Depois da retirada da cabeça, das vísceras e da pele, a cabrinha inteira, obtida de indústrias pesqueiras da cidade de Rio Grande - RS, foi filetada a fim de ser utilizada como matériaprima. Os filés foram moídos em moedor de carne doméstico. 
O filé moído foi lavado três vezes com água destilada, suficiente para cobri-lo, dentro de recipientes em banho de gelo $\left(7{ }^{\circ} \mathrm{C}\right)$, sob agitação manual constante durante cinco minutos. Depois de cada lavagem, a água foi retirada por prensagem em panos de algodão, tendo-se então a polpa lavada úmida (PU).

A polpa úmida foi triturada em multiprocessador (Mega Master Plus, Walita) para facilitar a incorporação à massa, sendo denominada de polpa lavada homogeneizada. Em seguida, foi realizada a secagem da polpa em estufa de circulação forçada de ar (modelo Q314M, Quimis) a $60{ }^{\circ} \mathrm{C}$, durante aproximadamente sete horas, sendo este período determinado como o melhor, através de curva de secagem. A polpa seca (PS) foi posteriormente triturada em liquidificador de facas duplas (pic-liq, Arno) e uniformizada em peneiras Tyler 20 (0,85 mm), obtendo-se finalmente a polpa lavada seca em pó.

A polpa úmida (PU) sofreu um processo de homogeneização em multiprocessador (modelo Mega Marte Plus, Walita) por um período de aproximadamente um minuto até a obtenção da polpa homogeneizada com consistência de creme a fim de ser melhor incorporada à massa. O esquema geral do processo de obtenção das polpas pode ser visualizado na Figura 1.

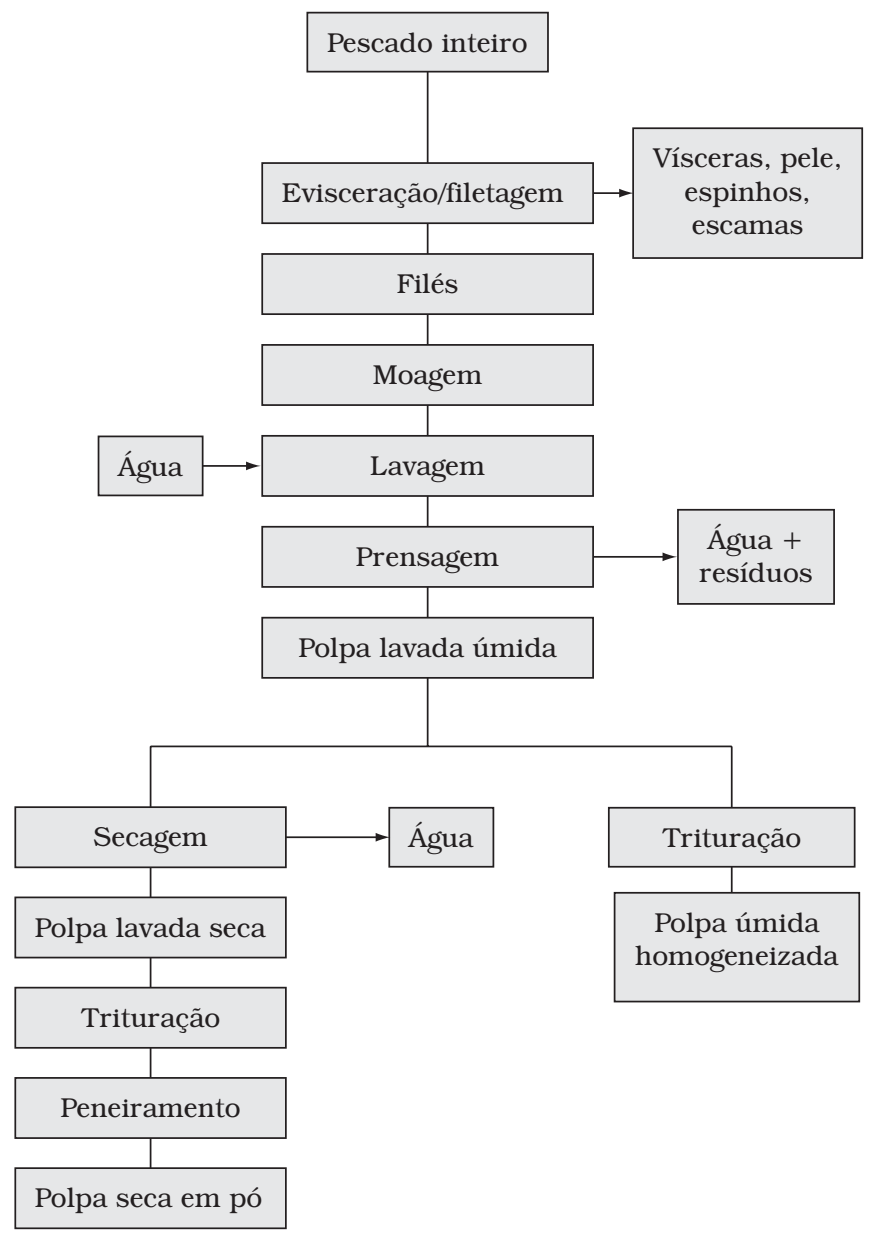

Figura 1. Processo de obtenção dos diferentes tipos de polpa de pescado.

\subsection{Rendimento do processo de obtenção das polpas de pescado}

O rendimento das polpas úmidas e secas foi determinado a partir do pescado inteiro até se obter a polpa utilizada na etapa de elaboração dos pães.

\subsection{Formulação dos pães}

Foram elaborados pães com 30, 40 e 50\% de polpa úmida (PU) e 3 e $5 \%$ de polpa seca (PS). As polpas foram adicionadas nas diferentes concentrações em base de farinha de trigo. Os pães foram elaborados conforme as formulações apresentadas na Tabela 1 , baseadas no pão padrão ${ }^{5}$.

Tabela 1. Formulação dos pães.

\begin{tabular}{lcccccc}
\hline \multirow{2}{*}{ Ingredientes (g) } & \multicolumn{7}{c}{ Formulações* } \\
\cline { 2 - 7 } & Padrão & 1 & 2 & 3 & 4 & 5 \\
\hline Farinha de trigo & 100 & 70 & 60 & 50 & 97 & 95 \\
Fermento biológico & 4 & 4 & 4 & 4 & 4 & 4 \\
Açúcar & 5 & 5 & 5 & 5 & 5 & 5 \\
Sal & 2 & 2 & 2 & 2 & 2 & 2 \\
Gordura & 2 & 2 & 2 & 2 & 2 & 2 \\
Vitamina C & 0,009 & 0,009 & 0,009 & 0,009 & 0,009 & 0,009 \\
PU & - & 30 & 40 & 50 & - & - \\
PS & - & - & - & - & 3 & 5 \\
Água & 57 & 12 & 8 & 4 & 62 & 64 \\
\hline * Pão Padrão = sem adição de polpa; 1 = Pão com 30\% PU; 2 = Pão com 40\% PU; 3 = Pão \\
com 50\% PU; 4 = Pão com 3\% de PS; e 5 = Pão com 5\% de PS.
\end{tabular}

\subsection{Elaboração dos pães}

Na elaboração dos pães, tanto a PU quanto a PS, foram adicionadas em diferentes concentrações durante a fase inicial da mistura dos ingredientes secos (farinha, sal, açúcar, vitamina C). Em seguida, foram adicionadas levedura e gordura à mistura, a qual foi homogeneizada em batedeira planetária (modelo BPA, Arno) durante nove minutos até o completo desenvolvimento do glúten. Foi necessária a adição de uma quantidade de água, que variou de acordo com a quantidade de polpa, necessária para atingir a consistência da massa padrão que contivesse $57 \%$ de água (v. $\mathrm{p}^{-1}$ ). A massa do pão foi cortada em porções de $150 \mathrm{~g}$, boleada e moldada. A seguir, as massas foram acomodadas em formas metálicas $(15,5 \times 7,5 \times 4,5 \mathrm{~cm})$ e levadas à fermentação durante 95 minutos, a $30{ }^{\circ} \mathrm{C}$ em incubadora bacteriológica (NR. 864045, Labor Cedate). Por fim, os pães foram forneados durante vinte minutos a $180{ }^{\circ} \mathrm{C} \mathrm{em}$ forno elétrico (modelo Diplomata 09.01.09, Fischer), resfriados durante uma hora e avaliados sensorial, tecnológica e físicoquimicamente.

\subsection{Avaliação sensorial}

A avaliação sensorial dos pães adicionados de 30, 40 e 50\% de PU e 3 e $5 \%$ de PS foi realizada mediante o uso do teste de ordenação ${ }^{8}$, com 39 julgadores. Depois do teste de ordenação, as amostras que obtiveram melhor aceitação (pães com 50\% de PU e 3 e $5 \%$ de PS) foram submetidas a uma nova avaliação mediante escala hedônica de 9 pontos ${ }^{8}$, com 30 julgadores. Em seguida, as amostras selecionadas (pães com $50 \%$ de PU e $5 \%$ 
de PS) e o pão padrão foram avaliados por 17 julgadores treinados mediante teste de perfil de atributos, sendo eles, aroma, sabor, textura do miolo, estrutura da célula do miolo, forma e simetria. Todos julgadores eram consumidores diários de pão, possuíam de 15 a 50 anos, de ambos os sexos, escolhidos de modo aleatório, sem conhecimento sobre a composição das amostras. Apenas o teste de perfil de atributos foi composto de julgadores treinados. Os resultados do teste de ordenação foram avaliados pelo teste de Friedman ao nível de 5\% de significância; os da escala hedônica foram normatizados através das respostas dos julgadores, avaliados pela ANOVA, sendo as médias comparadas pelo teste de Tukey $(\mathrm{p}<0,05)$; os resultados do teste de perfil de atributos foram também avaliados pela ANOVA e as médias comparadas pelo teste de Tukey, ao nível de $5 \%$ de significância.

\subsection{Avaliação tecnológica}

O volume específico $\left(\mathrm{mL} \cdot \mathrm{g}^{-1}\right)$ dos pães foi obtido pela razão entre o volume aparente $(\mathrm{mL})$, realizado por deslocamento de sementes $^{9}$, e a massa do pão após o forneamento (g). As notas das características internas (cor do miolo, estrutura da célula do miolo, textura), externas (característica da crosta, cor da crosta, quebra, simetria), aroma e sabor dos pães foram avaliados segundo planilha de EL-DASH, totalizando ao final o máximo de 100 pontos $^{5}$. Todos os resultados foram tratados estatisticamente pela ANOVA, sendo as médias, das notas e dos volumes específicos, comparadas entre si pelo teste de Tukey $(\mathrm{p}<0,05)$.

\subsection{Avaliação físico-química}

O filé de cabrinha, a polpa de pescado, e os pães padrão e enriquecidos tiveram sua composição proximal determinada de acordo com a metodologia oficial da $\mathrm{AOAC}^{1}$, em que os lipídios foram determinados pelo método de Soxhlet, proteína total pelo método de Kjeldahl, (\%N x 6,25 para o pescado e \%N x 5,7 para os pães). As cinzas (mufla $550-600{ }^{\circ} \mathrm{C}$ ) e a umidade (estufa $105^{\circ} \mathrm{C}$ ) foram determinadas por método gravimétrico.

\section{Resultados e discussão}

\subsection{Obtenção da polpa de pescado}

A partir dos filés de cabrinha, foram obtidas polpas conforme observado nas Figuras 2 e 3. A polpa de cor branca (b) foi denominada de polpa lavada e apresentou uma diminuição do odor característico a pescado, comparada com a polpa não lavada (a), enquanto que a polpa seca apresentou a aparência de uma farinha de cor levemente amarelada.

\subsection{Rendimento das polpas úmida e seca}

A Tabela 2 mostra os valores de rendimento das etapas do processo de obtenção da polpa úmida e seca em relação à cabrinha inteira.

Os resultados obtidos com os cálculos de rendimento mostraram que houve um pequeno aumento no rendimento da polpa úmida (34\%) comparado ao filé moído $(31,6 \%)$, devido
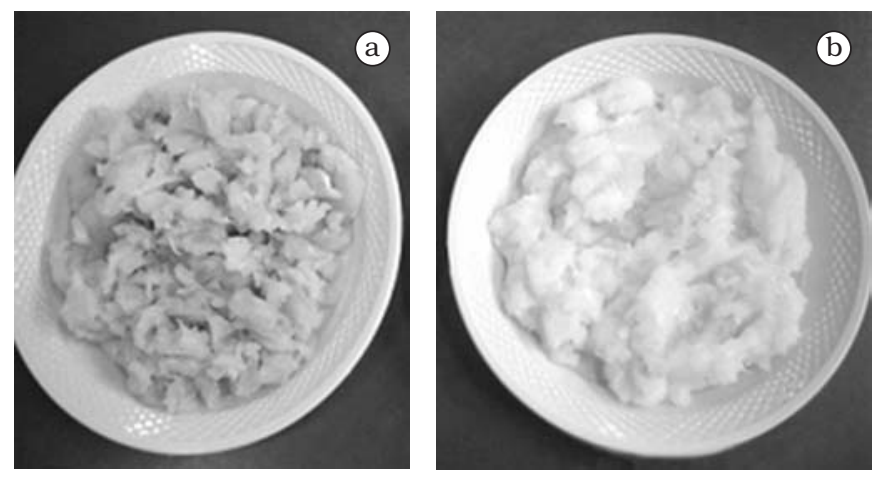

Figura 2. Polpa moída de cabrinha a) antes; e b) após lavagem.

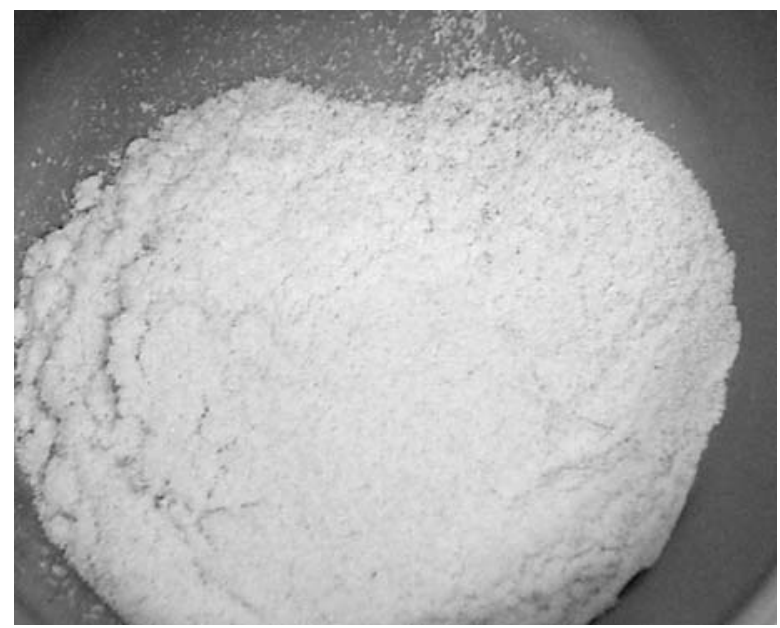

Figura 3. Polpa seca

Tabela 2. Rendimento das etapas do processo de obtenção da polpa de cabrinha.

\begin{tabular}{lc}
\hline \multicolumn{1}{c}{ Porção } & Rendimento $\left(\mathrm{g} .100 \mathrm{~g}^{-1}\right.$ ) \\
\hline Pescado inteiro & 100 \\
Filé moído & 31,6 \\
Polpa lavada úmida (PU) & 34,0 \\
Polpa lavada seca (PS) & 3,7 \\
\hline
\end{tabular}

à absorção de água pela carne durante o processo de lavagem, aumentando assim seu peso. Já a polpa seca, apresentou um rendimento de $3,7 \%$ em relação ao pescado inteiro, considerado baixo quando comparado ao rendimento da polpa úmida e do filé moído. O baixo rendimento das polpas úmida e seca, comparadas com o pescado inteiro, também se deve a perdas durante algumas operações do processo. Além disso, a cabrinha possui aproximadamente um terço de sua estrutura formada pela cabeça, o que diminui o rendimento em todas as etapas da obtenção da polpa.

\subsection{Avaliação sensorial}

A partir do teste sensorial de ordenação, encontrou-se o valor crítico de Friedman (igual a 39), abaixo do qual não há diferença significativa segundo a preferência. Verificou-se que apenas os pães com 30 e $40 \%$ de PU diferiram significativamente do pão com $5 \%$ de PS, o qual foi considerado melhor, segundo os julgadores. Assim, foram eliminados os pães adicionados de 
30 e $40 \%$ de PU por serem os menos aceitos, sendo selecionados os pães com $50 \%$ de PU, $3 \%$ e $5 \%$ de PS, que foram submetidos ao teste da escala hedônica de 9 pontos para avaliar a aceitação dos 30 julgadores, conforme Figura 4.

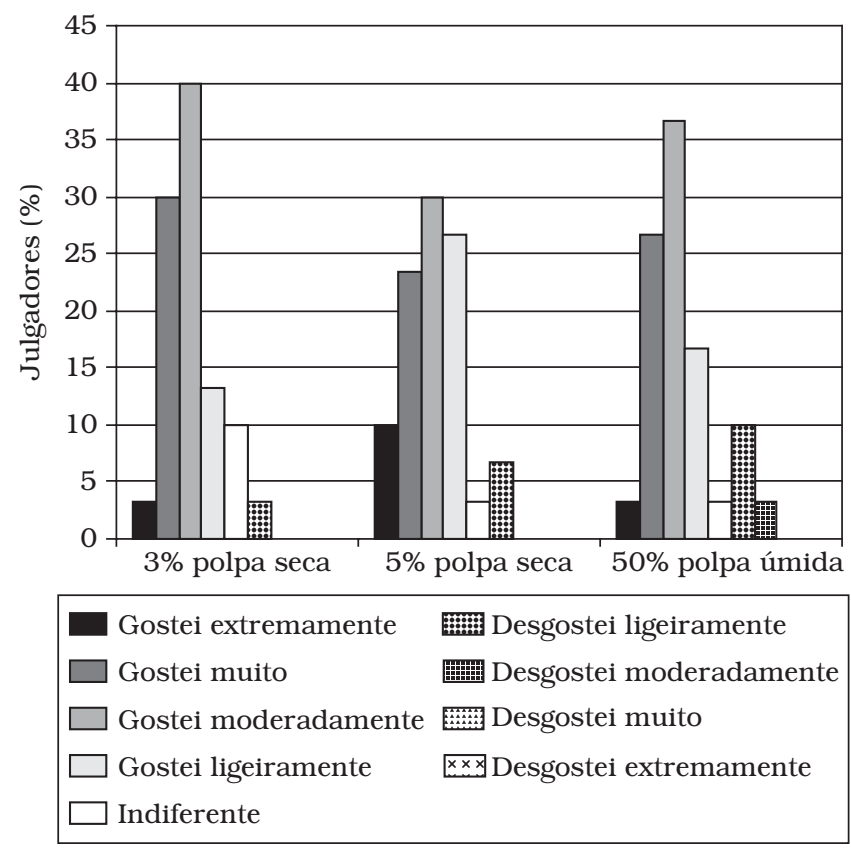

Figura 4. Freqüência das respostas do teste da escala hedônica de pães.

A maioria dos julgadores "gostou moderadamente" das três amostras avaliadas e nenhum "desgostou muito" ou "desgostou extremamente". A formulação de pão contendo $3 \%$ de PS obteve o maior número de respostas para "gostei moderadamente" (40\%) e "gostei muito" (30\%). Entretanto, os índices de aceitação dos pães com 3\% PS, $5 \%$ PS e $50 \%$ PU que foram respectivamente $77,0,76,7$ e $74,1 \%$, mostraram que não houve diferença significativa ( $\mathrm{p}<0,05$ ) entre as três formulações. Foi verificado ainda que, à medida que se aumentava a concentração da polpa na formulação, havia uma tendência de rejeição por parte dos julgadores, devido ao forte gosto a pescado, principalmente nos pães adicionados de polpa seca. SIDWELL e HAMMERLE ${ }^{11}$, trabalhando com concentrado protéico de pescado (CPP), também demonstraram que as proteínas do pescado interferiram nas características reológicas e sensoriais dos pães enriquecidos.

Como foi observado que pelo teste de aceitação não houve diferença significativa entre os pães com 3 e 5\% de PS, o pão adicionado de $5 \%$ de PS foi escolhido para a realização do teste descritivo quantitativo de perfil de atributos (Figura 5), por conter maior quantidade de polpa, juntamente com o pão contendo $50 \%$ de PU e o pão padrão.

O pão adicionado de PS não diferiu significativamente do padrão para nenhum atributo avaliado, mas o pão com PU apresentou uma diferença significativa do padrão nos atributos textura do miolo, aroma e sabor, resultados estes semelhantes aos descritos por SIDWELL e HAMMERLE ${ }^{11}$, que concluíram

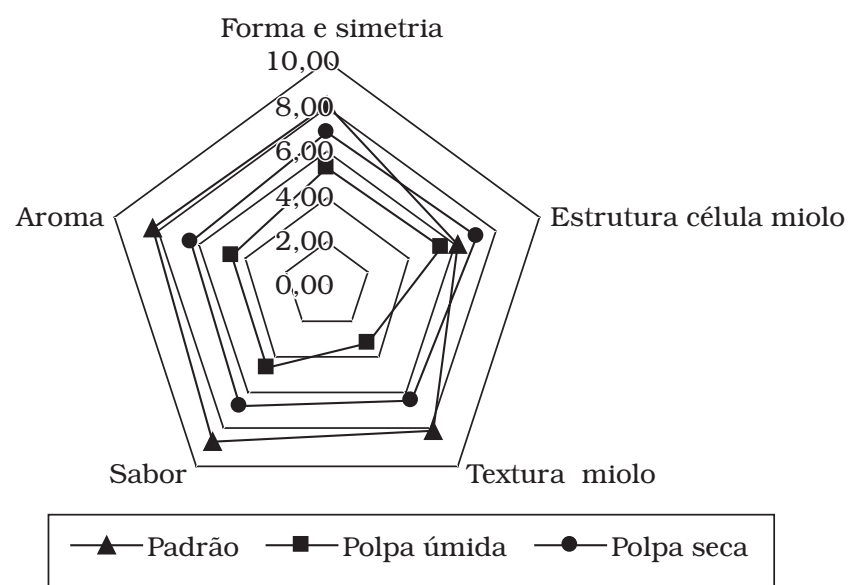

Figura 5. Gráfico radar dos atributos avaliados dos pães enriquecidos comparados com o pão padrão.

que uma adição de $10 \%$ ou mais de CPP alterou a textura dos pães tornando a massa grosseira e compacta.

\subsection{Avaliação tecnológica}

Os pães selecionados com 3 e $5 \%$ de polpa seca e $50 \%$ de polpa úmida obtiveram notas das características internas e externas, segundo planilha de 100 pontos de EL-DASH ${ }^{5}$ de 70, 53 e 62 e volume específico de 4,08, 3,32 e 2,29 mL.g ${ }^{-1}$, respectivamente (Figura 6); valores que diferiram significativamente $(\mathrm{p}<0,05)$ entre si para as três formulações.

Observou-se que o pão com $3 \%$ de PS apresentou melhor qualidade tecnológica, devido às maiores notas e melhor volume específico em relação aos demais pães, uma vez que a polpa seca se apresentou como uma "farinha", incorporando-se melhor aos ingredientes da massa. Do contrário, a PU não se incorporou integralmente à mistura, dificultando o desenvolvimento da massa do pão, diminuindo o volume específico e as notas das características tecnológicas, o que também foi mostrado por SIDWELL e HAMMERLE ${ }^{11}$, que conforme a adição de CPP havia uma diminuição no volume dos pães, além de apresentarem uma coloração escura e aparência abatumada. No presente trabalho, o pão com PU mostrou melhor sabor do que as demais formulações de PS de acordo com os julgadores, no entanto perdia notas nos atributos forma e simetria, características da crosta, cor do miolo e volume específico.

\subsection{Avaliação físico-química}

A Tabela 3 mostra a composição centesimal da PU e PS de cabrinha utilizada na elaboração dos pães.

Tabela 3. Composição centesimal das polpas úmida (PU) e seca (PS) de cabrinha.

\begin{tabular}{crr}
\hline Componente (\%) & PU & \multicolumn{1}{c}{ PS } \\
\hline Umidade & 89,0 & 8,2 \\
Proteína & 9,1 & 82,2 \\
Lipídios & 0,6 & 6,2 \\
Cinzas & 0,3 & 2,1 \\
\hline
\end{tabular}



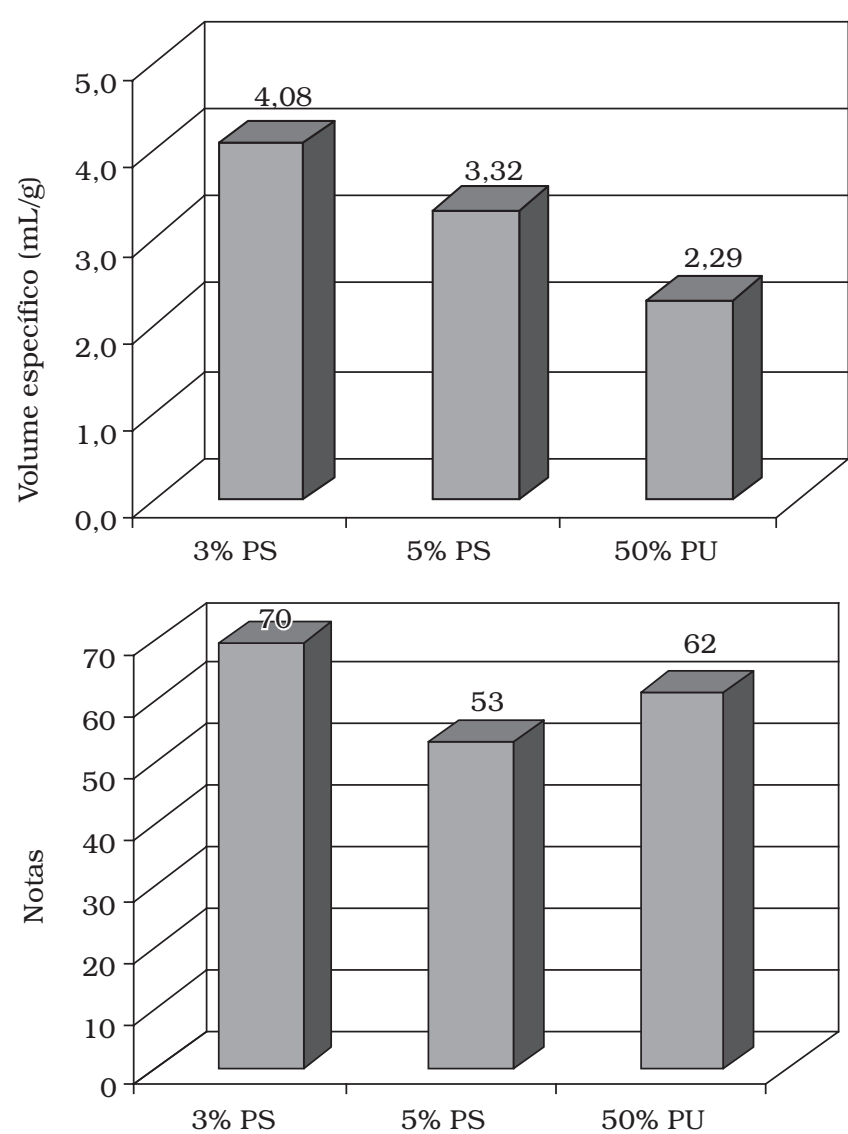

Figura 6. a) Volumes específicos; e b) notas tecnológicas dos pães enriquecidos.

Conforme a Tabela 3, a PU apresentou uma baixa concentração de lipídios, proteínas e cinzas, sendo que após a secagem (PS), estes nutrientes foram concentrados, principalmente a proteína, que era o componente desejado para ser incorporado ao pão, que variou de 9,1 para $82,2 \%$. $\mathrm{BIANCHI}^{2}$, trabalhando com polpa lavada de cabrinha também observou aumento do conteúdo protéico da PU e PS, de 9,4 para $86,4 \%$, respectivamente. Vale ressaltar ainda o baixo conteúdo lipídico da matéria-prima, diminuindo assim a probabilidade de rancificação da PS. Para isso, seria recomendado efetuar um teste de vida útil em trabalhos futuros, para verificar alterações em um maior tempo de estocagem em relação ao pão padrão.

A Tabela 4 mostra a composição proximal dos pães em base seca (b.s.) contendo 3 e $5 \%$ de PS e $50 \%$ de PU.

Tabela 4. Composição proximal do pão padrão e dos pães com polpa.

\begin{tabular}{lrrrr}
\hline \multirow{2}{*}{ Componentes } & \multicolumn{4}{c}{ Pão } \\
\cline { 2 - 5 } & Padrão & $3 \%$ PS & $5 \%$ PS & $50 \%$ PU \\
\hline Umidade & $34,2^{\mathrm{a}}$ & $31,9^{\mathrm{b}}$ & $32,9^{\mathrm{c}}$ & $30,4^{\mathrm{d}}$ \\
Proteínas (b.s.) & $11,8^{\mathrm{a}}$ & $15,5^{\mathrm{b}}$ & $17,1^{\mathrm{c}}$ & $17,5^{\mathrm{c}}$ \\
Lipídios (b.s.) & $2,3^{\mathrm{a}}$ & $2,4^{\mathrm{a}}$ & $2,8^{\mathrm{a}}$ & $2,0^{\mathrm{a}}$ \\
Cinzas (b.s.) & $2,4^{\mathrm{a}}$ & $2,5^{\mathrm{a}}$ & $2,5^{\mathrm{a}}$ & $2,2^{\mathrm{b}}$ \\
Carboidratos * (b.s.) $^{\mathrm{a}}$ & $83,5^{\mathrm{a}}$ & $79,6^{\mathrm{b}}$ & $77,6^{\mathrm{b}}$ & $78,3^{\mathrm{b}}$ \\
\hline
\end{tabular}

${ }^{*}$ por diferença. Letras iguais, na mesma linha, indicam que não há diferença signnificativa entre as médias pelo teste de Tukey ( $\mathrm{p}<0,05)$
Letras iguais, na mesma linha, indicam que não há diferença significativa entre as médias pelo teste de Tukey $(\mathrm{p}<0,05)$.

Observou-se que o conteúdo protéico de todos os pães adicionados de polpa foi significativamente maior que o pão padrão. Comparando os nutrientes dos pães adicionados de $5 \%$ PS e 50\% PU, foi observado que os teores de proteínas, lipídios e carboidratos não apresentaram diferença significativa entre si, indicando que tanto a polpa seca quanto a polpa úmida, quando adicionadas nessas porcentagens, implicam em um conteúdo nutricional semelhante. O pão com 3\% de PS apresentou um conteúdo protéico inferior aos demais pães adicionados de polpa. O pão com $50 \%$ de PU apresentou conteúdo de minerais inferior aos demais pães, devido à maior quantidade de água presente na polpa, ocasionando diluição dos nutrientes.

A Tabela 5 apresenta o aumento da proteína nos pães com polpa de pescado em relação à proteína do pão padrão.

Tabela 5. Aumento (\%) das proteínas dos pães com polpa em relação à proteína do pão padrão.

\begin{tabular}{cc}
\hline Pão & Base seca (\%) \\
\hline $3 \%$ de PS & $31^{\mathrm{a}}$ \\
$5 \%$ de PS & $45^{\mathrm{b}}$ \\
$50 \%$ de PU & $48^{\mathrm{b}}$ \\
\hline
\end{tabular}

Letras iguais indicam que não há diferença significativa pelo teste de Tukey $(\mathrm{p}<0,05)$.

Os pães com $5 \%$ de PS e $50 \%$ de PU não apresentaram diferença significativa entre si (Tabela 5), mostrando maior aumento protéico em relação ao pão padrão, do que a formulação com $3 \%$ de PS.

\section{Conclusões}

Todos os pães formulados apresentaram boa aceitação sensorial, apesar das características tecnológicas terem sido prejudicadas quando se adicionou mais de 3\% PS nos pães devido ao acréscimo de polpa de pescado na formulação. No entanto, houve um aumento considerável do conteúdo protéico, que era o principal objetivo, a partir de uma espécie de pescado de baixo valor comercial. Dessa maneira, nas condições experimentais realizadas, pode-se concluir que a adição de polpa de pescado em pães pode contribuir para o enriquecimento protéico de produtos de panificação.

\section{Agradecimentos}

Às Indústrias Pescal S.A. e Paulo Heep Pescados, pelo fornecimento da matéria-prima.

\section{Referências bibliográficas}

1. AOAC, OFFICIAL METHODS OF ANALYSIS. Association of Official Analytical Chemists, 16. ed., v. 1-2, USA, 1995.

2. BIANCHI, S. I. P. Influência da Secagem nas Propriedades Funcionais da Polpa de Pescado. Rio Grande, 2006, $190 \mathrm{f.}$. Dissertação (Mestrado em Engenharia e Ciência de Alimentos) Fundação Universidade Federal do Rio Grande (FURG).

3. BRASIL. Portaria n.31, de 13 de janeiro de 1998. Regulamento Técnico para Fixação de Identidade e Qualidade de Alimentos Adicionados de Nutrientes Essenciais. Diário Oficial da União, 
Brasília, DF, 13 jan. 1998. Disponível em: <http://e-legis.bvs.br/ leisref/public/showAct.php?id=64>. Acesso em: 2 out. 2006.

4. DINIZ, F. M.; MARTIN, A. M. Use of response surface methodology to describe the combined effects of $\mathrm{pH}$, temperature and $\mathrm{E} / \mathrm{S}$ ratio on the hydrolysis of dogfish (Squalus acanthias) muscle. International Journal of Food Science and Technology, v. 31, n. 5, p. 419-426, 1996.

5. EL-DASH, A. A. Standardized mixing and fermentation procedure for experimental baking test; Cereal Chemistry, v. 55, n. 4 , p. $436-446,1978$.

6. ILYAS, M. et al. The effect of iron fortification on the quality of fortified bread. Sarhad Journal of Agricultural, v. 12, n. 2, 1996.

7. KRISTINSSON, H. G.; RASCO, B. A. Fish Protein Hydrolysates: Production, Biochemical and Functional Properties. Critical
Reviews in Food Science and Nutrition, v. 40, n. 1, p. 43-81, 2000.

8. LAWLESS, H. T.; HEYMANN, H. Sensory Evaluation of Food: Principles and Practices. Aspen Publication, Maryland, 1999.

9. PIZZINATTO, A. et al. Avaliação tecnológica de produtos derivados de farinhas de trigo (pão, macarrão, biscoito). Centro de Tecnologia de Farinhas e Panificação, Instituto de Tecnologia de Alimentos (ITAL), 54p. Campinas, SP, 1993.

10. REILLY, C. Too much of a good thing? The problem of trace element fortification of foods. Trends in Food Science \& Technology, v. 7, p.139-142, 1996.

11. SIDWELL, V. D.; HAMMERLE, O. A. Changes in Physical and Sensory Characteristics of Doughs and of Bread Containing Various Amounts of Fish Protein Concentrate and Lysine. Cereal Chemistry, v. 47, p. 739-745, 1970. 